\title{
An optimization problem involving proximal quasi-contraction mappings
}

\author{
Mohamed Jleli and Bessem Samet ${ }^{*}$
}

${ }^{*}$ Correspondence:

bsamet@ksu.edu.sa

Department of Mathematics, King

Saud University, Riyadh, Saudi

Arabia

\begin{abstract}
Consider a non-self-mapping $T: A \rightarrow B$, where $(A, B)$ is a pair of nonempty subsets of a metric space $(X, d)$. In this paper, we study the existence and uniqueness of solutions to the global optimization problem $\min _{x \in A} d(x, T x)$, where $T$ belongs to the class of proximal quasi-contraction mappings.
\end{abstract}

MSC: $41 \mathrm{~A} 65 ; 90 \mathrm{C} 30 ; 47 \mathrm{H} 10$

Keywords: global optimization; best proximity; proximal quasi-contraction; proximal Picard sequence; T-orbitally complete

\section{Introduction}

Let $(X, d)$ be a metric space and $(A, B)$ be a pair of nonempty subsets of $X$. Consider a non-self-mapping $T: A \rightarrow B$. An element $x^{*} \in A$ is said to be a best proximity point of the mapping $T$ iff $d\left(x^{*}, T x^{*}\right)=\inf \{d(a, b): a \in A, b \in B\}$. Clearly, if $A=B$, a best proximity point of $T$ will be a fixed point of $T$. The aim of best proximity point analysis is to provide sufficient conditions assuring the existence and uniqueness of best proximity points, and build algorithms that can serve to approximate such points.

In [1], Sankar Raj introduced the concept of $P$-property and obtained a best proximity point result for a class of weakly non-self-contractive mappings. Later on, many authors considered different classes of contractive mappings under the $P$-property (see, e.g., [2$4])$. Very recently, Abkar and Gabeleh [5] observed that the most best proximity point theorems obtained under the $P$-property can be deduced from existing fixed point results in the literature.

In [6], Sadiq Basha presented an extension of Banach's contraction principle via a best proximity point theorem under the assumption: $B$ is approximatively compact with respect to $A$. Later on, various best proximity point results are derived under this assumption (see, e.g., [7-9]). In a recent work, Sadiq Basha and Shahzad [9] established new best proximity point results for generalized proximal contractions of first and second kind. For other results on best proximity point analysis, we refer the reader to [10-19].

This paper discusses the existence and uniqueness of best proximity points for a new class of non-self-mappings. More precisely, we introduce in this work the class of proximal quasi-contractive mappings, and we establish new best proximity point results for such mappings. In our results, we consider only proximal contractions of the first kind. Moreover, the compactness assumption, used in many previous works, is not assumed. We show that the results obtained in $[6,9]$ are particular cases of our main result.

○2014 Jleli and Samet; licensee Springer. This is an Open Access article distributed under the terms of the Creative Commons Attribution License (http://creativecommons.org/licenses/by/2.0), which permits unrestricted use, distribution, and reproduction in any medium, provided the original work is properly cited. 
The paper is organized as follows. In Section 2, we introduce the class of proximal quasi-contractive mappings, and the concept of proximal orbital completeness. Section 3 presents some useful lemmas that will be used to show that our proximal orbital completeness concept is weaker than the compactness condition imposed on the pair $(A, B)$, and the proximal condition of the second kind. In Section 4, we present and establish our main result. Finally, in Section 5, we show that many existing best proximity point results including the obtained results in $[6,9]$ are particular cases of our main theorem.

\section{Definitions}

Through this paper, $\mathbb{N}$ denotes the set of natural numbers, and $\mathbb{N}^{*}=\mathbb{N} \backslash\{0\}$.

Let $(X, d)$ be a metric space and $(A, B)$ a pair of nonempty subsets of $X$. We consider the following notations:

$$
\begin{aligned}
& d(A, B):=\inf \{d(a, b): a \in A, b \in B\} \\
& d(x, B):=\inf \{d(x, b): b \in B\} \\
& \Delta(A):=\sup \{d(a, b): a, b \in A\} ; \\
& A_{0}:=\{a \in A: d(a, b)=d(A, B) \text { for some } b \in B\} \\
& B_{0}:=\{b \in B: d(a, b)=d(A, B) \text { for some } a \in A\}
\end{aligned}
$$

Definition 2.1 An element $x^{*} \in A$ is said to be a best proximity point of the non-selfmapping $T: A \rightarrow B$ iff

$$
d\left(x^{*}, T x^{*}\right)=d(A, B)
$$

Reference [6] introduced the following concept.

Definition 2.2 We say that $B$ is approximatively compact with respect to $A$ iff every sequence $\left\{y_{n}\right\} \subset B$ satisfying the condition that $\lim _{n \rightarrow \infty} d\left(x, y_{n}\right)=d(x, B)$ for some $x$ in $A$, has a convergent subsequence.

Reference [9] introduced the following concepts.

Definition 2.3 A non-self-mapping $T: A \rightarrow B$ is said to be a generalized proximal contraction of the first kind iff there exist non-negative numbers $\alpha, \beta, \gamma, \delta$ with $\alpha+\beta+\gamma+2 \delta<$ 1 such that

$$
\left.\begin{array}{l}
d(u, T x)=d(A, B) \\
d(v, T y)=d(A, B)
\end{array}\right\} \quad \Longrightarrow \quad d(u, v) \leq \alpha d(x, y)+\beta d(x, u)+\gamma d(y, v)+\delta(d(x, v)+d(y, u))
$$

where $x, y, u, v \in A$.

Definition 2.4 A non-self-mapping $T: A \rightarrow B$ is said to be a generalized proximal contraction of the second kind iff there exist non-negative numbers $\alpha, \beta, \gamma$, with 
$\alpha+\beta+\gamma+2 \delta<1$ such that

$$
\begin{gathered}
\left.\begin{array}{c}
d(u, T x)=d(A, B) \\
d(v, T y)=d(A, B)
\end{array}\right\} \Rightarrow d(T u, T v) \leq \\
\alpha d(T x, T y)+\beta d(T x, T u)+\gamma d(T y, T v) \\
+\delta(d(T x, T v)+d(T y, T u)),
\end{gathered}
$$

where $x, y, u, v \in A$.

In this paper, we introduce the following concepts.

Definition 2.5 A non-self-mapping $T: A \rightarrow B$ is said to be a proximal quasi-contraction iff there exists a number $q \in[0,1)$ such that

$$
\left.\begin{array}{l}
d(u, T x)=d(A, B) \\
d(v, T y)=d(A, B)
\end{array}\right\} \quad \Longrightarrow \quad d(u, v) \leq q \max \{d(x, y), d(x, u), d(y, v), d(x, v), d(y, u)\}
$$

where $x, y, u, v \in A$.

Remark 2.1 Clearly, we have the following implication: $T$ is a generalized proximal contraction of the first kind $\Rightarrow T$ is a proximal quasi-contraction.

If $T$ is a self-mapping on $A$, then the requirement in the preceding definition reduces to the condition that

$$
d(T x, T y) \leq q \max \{d(x, y), d(x, T x), d(y, T y), d(x, T y), d(y, T x)\},
$$

for all $x, y, u, v \in A$. Such condition was introduced by [20] under the name of quasicontraction.

Lemma 2.1 Let $T: A \rightarrow B$ be a non-self-mapping. Suppose that the following conditions hold:

(i) $A_{0} \neq \emptyset$;

(ii) $T\left(A_{0}\right) \subseteq B_{0}$.

Then, for all $a \in A_{0}$, there exists a sequence $\left\{x_{n}\right\} \subset A_{0}$ such that

$$
\left\{\begin{array}{l}
x_{0}=a, \\
d\left(x_{n+1}, T x_{n}\right)=d(A, B), \quad \forall n \in \mathbb{N} .
\end{array}\right.
$$

Proof Let $x_{0}=a$. Since $T\left(A_{0}\right) \subseteq B_{0}$, there exists $x_{1} \in A_{0}$ such that $d\left(x_{1}, T x_{0}\right)=d(A, B)$. Again, since $T x_{1} \in T\left(A_{0}\right) \subseteq B_{0}$, there exists $x_{2} \in A_{0}$ such that $d\left(x_{2}, T x_{1}\right)=d(A, B)$. Continuing this process, by induction, we can build a sequence $\left\{x_{n}\right\} \subset A_{0}$ satisfying (2.1).

Definition 2.6 Under the assumptions of Lemma 2.1, any sequence $\left\{x_{n}\right\} \subset A_{0}$ satisfying (2.1) is called a proximal Picard sequence associated to $a \in A_{0}$.

For every $a \in A_{0}$, we denote by $P P(a)$ the set of all proximal Picard sequences associated to $a$. 
Let $a \in A_{0}$ and $\left\{x_{n}\right\} \in P P(a)$. For all $(i, j) \in \mathbb{N}^{2}$, we define the following sets:

$$
\mathcal{O}\left(x_{i}, j\right):=\left\{x_{l}: i \leq l \leq j+i\right\}
$$

and

$$
\mathcal{O}\left(x_{i}, \infty\right):=\left\{x_{l}: l \geq i\right\}
$$

Definition 2.7 We say that $A_{0}$ is proximal $T$-orbitally complete iff every Cauchy sequence $\left\{x_{n}\right\} \in P P\left(x_{0}\right)$ for some $x_{0} \in A_{0}$, converges to an element in $A_{0}$.

If $T$ is a self-mapping on $A$, then the requirement in the preceding definition reduces to the condition that $A$ is $T$-orbitally complete (see [20]).

\section{Some useful lemmas}

The following preliminary results will be useful later.

Lemma 3.1 Let $(A, B)$ be a pair of closed subsets of a metric space $(X, d)$. Suppose that the following conditions hold:

(i) $A_{0} \neq \emptyset$;

(ii) $B$ is approximatively compact with respect to $A$.

Then the set $A_{0}$ is closed.

Proof Let $\left\{x_{n}\right\}$ be a sequence in $A_{0}$ such that

$$
\lim _{n \rightarrow \infty} d\left(x_{n}, x\right)=0
$$

for some $x \in A$. By the definition of $A_{0}$, there exists a sequence $\left\{b_{n}\right\}$ in $B$ such that

$$
d\left(x_{n}, b_{n}\right)=d(A, B), \quad \forall n \in \mathbb{N} .
$$

On the other hand, we have

$$
d(x, B) \leq d\left(x, b_{n}\right) \leq d\left(x, x_{n}\right)+d\left(x_{n}, b_{n}\right), \quad \forall n \in \mathbb{N} .
$$

Using (3.2), we get

$$
d(x, B) \leq d\left(x, b_{n}\right) \leq d\left(x, x_{n}\right)+d(A, B) \leq d\left(x, x_{n}\right)+d(x, B) .
$$

Letting $n \rightarrow \infty$ in the above inequalities and using (3.1), we obtain

$$
\lim _{n \rightarrow \infty} d\left(x, b_{n}\right)=d(x, B)
$$

Since $B$ is approximatively compact with respect to $A$, the sequence $\left\{b_{n}\right\}$ admits a convergent subsequence $\left\{b_{n_{k}}\right\}$. Let $b \in B$ such that

$$
\lim _{k \rightarrow \infty} d\left(b_{n_{k}}, b\right)=0
$$


From (3.1), (3.2), and (3.3), we get

$$
d(x, b)=\lim _{k \rightarrow \infty} d\left(x_{n_{k}}, b_{n_{k}}\right)=d(A, B)
$$

which implies that $x \in A_{0}$.

Lemma 3.2 Let $(A, B)$ be a pair of closed subsets of a complete metric space $(X, d)$. Let $T: A \rightarrow B$ be a non-self-mapping. Suppose that the following conditions hold:

(i) $A_{0} \neq \emptyset$;

(ii) $T\left(A_{0}\right) \subseteq B_{0}$;

(iii) $T$ is a generalized proximal contraction of the second kind.

Then $A_{0}$ is proximal $T$-orbitally complete.

Proof Let $x_{0} \in A_{0}$ and $\left\{x_{n}\right\} \in P P\left(x_{0}\right)$ be a Cauchy sequence. Since $(X, d)$ is complete and $A$ is closed, there exists $x \in A$ such that

$$
\lim _{n \rightarrow \infty} d\left(x_{n}, x\right)=0
$$

By definition of $P P\left(x_{0}\right)$, for all $n \in \mathbb{N}^{*}$, we have

$$
\left\{\begin{array}{l}
d\left(x_{n}, T x_{n-1}\right)=d(A, B), \\
d\left(x_{n+1}, T x_{n}\right)=d(A, B) .
\end{array}\right.
$$

Since $T$ is a generalized proximal contraction of the second kind, for all $n \in \mathbb{N}^{*}$, we have

$$
d\left(T x_{n}, T x_{n+1}\right) \leq \alpha d\left(T x_{n-1}, T x_{n}\right)+\beta d\left(T x_{n-1}, T x_{n}\right)+\gamma d\left(T x_{n}, T x_{n+1}\right)+\delta d\left(T x_{n-1}, T x_{n+1}\right) .
$$

Using the above inequality and the triangular inequality, we obtain

$$
d\left(T x_{n}, T x_{n+1}\right) \leq \lambda d\left(T x_{n-1}, T x_{n}\right), \quad \forall n \in \mathbb{N}^{*},
$$

where (from $\alpha+\beta+\gamma+2 \delta<1)$

$$
0 \leq \lambda:=\frac{\alpha+\beta+\delta}{1-\gamma-\delta}<1
$$

Using a standard technique of iterations, one can show that $\left\{T x_{n}\right\}$ is a Cauchy sequence. Since $(X, d)$ is complete and $B$ is closed, there exists $y \in B$ such that

$$
\lim _{n \rightarrow \infty} d\left(T x_{n}, y\right)=0
$$

Now, from (3.4) and (3.5), we have

$$
d(A, B)=\lim _{n \rightarrow \infty} d\left(x_{n+1}, T x_{n}\right)=d(x, y)
$$

which implies that $x \in A_{0}$. 


\section{Main result}

Our main result is giving by the following best proximity point theorem.

Theorem 4.1 Let $(A, B)$ be a pair of subsets of a metric space $(X, d)$. Let $T: A \rightarrow B$ be a giving mapping. Suppose that the following conditions hold:

(i) $A_{0} \neq \emptyset$;

(ii) $A_{0}$ is proximal $T$-orbitally complete;

(iii) $T\left(A_{0}\right) \subseteq B_{0}$;

(iv) $T$ is a proximal quasi-contraction.

Then $T$ has a unique best proximity point $x^{*} \in A_{0}$. Moreover, for any $x_{0} \in A_{0}$, any sequence $\left\{x_{n}\right\} \in P P\left(x_{0}\right)$ converges to $x^{*}$.

Proof Let $x_{0}$ be an arbitrary point in $A_{0}$. From Lemma 2.1, the set $P P\left(x_{0}\right)$ is nonempty. Let $\left\{x_{n}\right\} \in P P\left(x_{0}\right)$ be a proximal Picard sequence associated to $x_{0} \in A_{0}$. So, we have

$$
d\left(x_{n+1}, T x_{n}\right)=d(A, B), \quad \forall n \in \mathbb{N} .
$$

Clearly, if $x_{N+1}=x_{N}$ for some $N \in \mathbb{N}$, from (4.1), $x_{N}$ will be a best proximity point. So, we can suppose that

$$
d\left(x_{r}, x_{r+1}\right)>0, \quad \forall r \in \mathbb{N} .
$$

The proof is divided into several steps.

Step 1 . Giving $(s, n) \in \mathbb{N} \times \mathbb{N}^{*}$, we claim that for every pair $(i, j) \in \mathbb{N}^{2}$ with $1 \leq i \leq j \leq n$, we have

$$
d\left(x_{s+i}, x_{s+j}\right) \leq q \Delta\left(\mathcal{O}\left(x_{s+i-1}, j-i+1\right)\right) \leq q \Delta\left(\mathcal{O}\left(x_{s}, n\right)\right) .
$$

Let $(i, j) \in \mathbb{N}^{2}$ with $1 \leq i \leq j \leq n$. Using the fact that $T$ is a proximal quasi-contraction, from (4.1), we have

$$
\begin{aligned}
d\left(x_{s+i}, x_{s+j}\right) \leq & q \max \left\{d\left(x_{s+i-1}, x_{s+j-1}\right), d\left(x_{s+i-1}, x_{s+i}\right), d\left(x_{s+j-1}, x_{s+j}\right), d\left(x_{s+i-1}, x_{s+j}\right),\right. \\
& \left.d\left(x_{s+j-1}, x_{s+i}\right)\right\} \\
\leq & q \Delta\left(\mathcal{O}\left(x_{s+i-1}, j-i+1\right)\right) \\
\leq & q \Delta\left(\mathcal{O}\left(x_{s}, n\right)\right) .
\end{aligned}
$$

This proves our claim.

Step 2. We claim that

$$
\forall(s, n) \in \mathbb{N} \times \mathbb{N}^{*}, \exists j:=j(s, n) \in\{1,2, \ldots, n\} \mid \Delta\left(\mathcal{O}\left(x_{s}, n\right)\right)=d\left(x_{s}, x_{s+j}\right) .
$$

Let $(s, n) \in \mathbb{N} \times \mathbb{N}^{*}$ be fixed. By (4.2), there exists a pair $(i(s, n), j(s, n)) \in \mathbb{N}^{2}$ with

$$
0 \leq i:=i(s, n)<j:=j(s, n) \leq n
$$


such that

$$
0<\Delta\left(\mathcal{O}\left(x_{s}, n\right)\right)=d\left(x_{s+i}, x_{s+j}\right)
$$

Suppose that $i \neq 0$. From (4.3), we have

$$
\Delta\left(\mathcal{O}\left(x_{s}, n\right)\right)=d\left(x_{s+i}, x_{s+j}\right) \leq q \Delta\left(\mathcal{O}\left(x_{s}, n\right)\right)
$$

that is a contradiction with $q \in[0,1)$. Then $i=0$ and

$$
\Delta\left(\mathcal{O}\left(x_{s}, n\right)\right)=d\left(x_{s}, x_{s+j}\right)
$$

This proves our claim.

Step 3 . We claim that

$$
\Delta\left(\mathcal{O}\left(x_{0}, n\right)\right) \leq \frac{1}{1-q} d\left(x_{0}, x_{1}\right), \quad \forall n \in \mathbb{N}^{*} .
$$

From (4.4), we have

$$
\Delta\left(\mathcal{O}\left(x_{0}, n\right)\right)=d\left(x_{0}, x_{j}\right)
$$

for some $j=j(0, n) \in\{1,2, \ldots, n\}$. Now, using (4.3), we have

$$
\Delta\left(\mathcal{O}\left(x_{0}, n\right)\right)=d\left(x_{0}, x_{j}\right) \leq d\left(x_{0}, x_{1}\right)+d\left(x_{1}, x_{j}\right) \leq d\left(x_{0}, x_{1}\right)+q \Delta\left(\mathcal{O}\left(x_{0}, n\right)\right),
$$

which proves our claim.

Step 4 . We claim that $\left\{x_{n}\right\}$ is a Cauchy sequence.

Let $(n, m) \in \mathbb{N}^{2}$ with $1 \leq n<m$. Using (4.3), we have

$$
d\left(x_{n}, x_{m}\right)=d\left(x_{(n-1)+1}, x_{(n-1)+m-n+1}\right) \leq q \Delta\left(\mathcal{O}\left(x_{n-1}, m-n+1\right)\right) .
$$

On the other hand, from (4.4) we have

$$
\Delta\left(\mathcal{O}\left(x_{n-1}, m-n+1\right)\right)=d\left(x_{n-1}, x_{n-1+j}\right)
$$

for some $j \in\{1,2, \ldots, m-n+1\}$. Using (4.3), we obtain

$$
d\left(x_{n-1}, x_{n-1+j}\right)=d\left(x_{(n-2)+1}, x_{(n-2)+j+1}\right) \leq q \Delta\left(\mathcal{O}\left(x_{n-2}, m-n+2\right)\right) .
$$

Thus we have

$$
\Delta\left(\mathcal{O}\left(x_{n-1}, m-n+1\right)\right) \leq q \Delta\left(\mathcal{O}\left(x_{n-2}, m-n+2\right)\right) .
$$

From (4.6) and (4.7), we obtain

$$
d\left(x_{n}, x_{m}\right) \leq q^{2} \Delta\left(\mathcal{O}\left(x_{n-2}, m-n+2\right)\right) .
$$


Continuing this process, by induction, we get

$$
d\left(x_{n}, x_{m}\right) \leq q^{n} \Delta\left(\mathcal{O}\left(x_{0}, m\right)\right)
$$

Thanks to (4.5), we obtain

$$
d\left(x_{n}, x_{m}\right) \leq \frac{q^{n}}{1-q} d\left(x_{0}, x_{1}\right)
$$

which implies (since $q \in[0,1)$ ) that the proximal Picard sequence $\left\{x_{n}\right\}$ is Cauchy.

Step 5. Existence of a best proximity point.

Since $A_{0}$ is proximal $T$-orbitally complete, the sequence $\left\{x_{n}\right\}$ converges to some element $x^{*} \in A_{0}$. Since $T\left(A_{0}\right) \subseteq B_{0}$, there exists $u \in A_{0}$ such that

$$
d\left(u, T x^{*}\right)=d(A, B)=d\left(x_{n+1}, T x_{n}\right), \quad \forall n \in \mathbb{N} .
$$

Since $T$ is a proximal quasi-contraction, we have

$$
d\left(u, x_{n+1}\right) \leq q \max \left\{d\left(x^{*}, x_{n}\right), d\left(x^{*}, u\right), d\left(x_{n}, x_{n+1}\right), d\left(x^{*}, x_{n+1}\right), d\left(x_{n}, u\right)\right\} .
$$

Letting $n \rightarrow \infty$ in the above inequality, we obtain

$$
d\left(x^{*}, u\right) \leq q d\left(x^{*}, u\right),
$$

which holds only if $d\left(x^{*}, u\right)=0$, that is, $u=x^{*}$. So, we have $d\left(x^{*}, T x^{*}\right)=d\left(u, T x^{*}\right)=d(A, B)$, which means that $x^{*} \in A_{0}$ is a best proximity point of $T$.

Step 6 . Uniqueness of the best proximity point.

Suppose that $y^{*} \in A_{0}$ is another best proximity point, that is,

$$
\left\{\begin{array}{l}
d\left(x^{*}, T x^{*}\right)=d(A, B), \\
d\left(y^{*}, T y^{*}\right)=d(A, B) .
\end{array}\right.
$$

Using the fact that $T$ is a proximal quasi-contraction, we obtain the following inequality:

$$
d\left(x^{*}, y^{*}\right) \leq q \max \left\{d\left(x^{*}, y^{*}\right), d\left(x^{*}, x^{*}\right), d\left(y^{*}, y^{*}\right), d\left(x^{*}, y^{*}\right), d\left(y^{*}, x^{*}\right)\right\}=q d\left(x^{*}, y^{*}\right),
$$

which holds only if $d\left(x^{*}, y^{*}\right)=0$, that is, $x^{*}=y^{*}$.

Example 4.1 Consider the Euclidean space $\mathbb{R}^{2}$ endowed with the standard metric:

$$
d\left(\left(x_{1}, y_{1}\right),\left(x_{2}, y_{2}\right)\right)=\left|x_{1}-x_{2}\right|+\left|y_{1}-y_{2}\right|, \quad \forall\left(x_{1}, y_{1}\right),\left(x_{2}, y_{2}\right) \in \mathbb{R}^{2} .
$$

Let us define

$$
A:=\left\{(0, \alpha) \in \mathbb{R}^{2}: 0 \leq \alpha \leq 1\right\} ; \quad B:=\left\{(1, \beta) \in \mathbb{R}^{2}: 0 \leq \beta \leq 1\right\} .
$$

Clearly $(A, B)$ is a pair of closed subsets of $\left(\mathbb{R}^{2}, d\right)$ with $A_{0}=A, B_{0}=B$ and $d(A, B)=1$ (see Figure 1). Moreover, since $A_{0}$ is a closed subset of the complete metric space $\left(\mathbb{R}^{2}, d\right)$, 
Figure 1 The pair $(A, B)$ of closed subsets of $\left(\mathbb{R}^{2}, d\right)$.

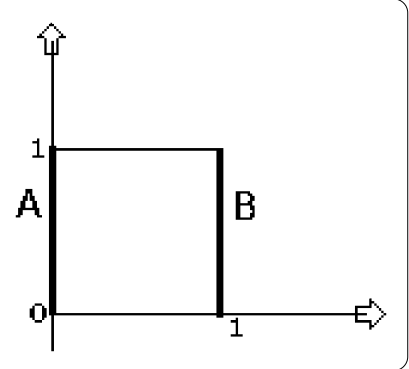

then $A_{0}$ is proximal $T$-orbitally complete for any mapping $T: A \rightarrow B$. Define the non-selfmapping $T: A \rightarrow B$ by

$$
T(0, \alpha):=(1, f(\alpha))
$$

where

$$
f(\alpha):= \begin{cases}\alpha / 4 & \text { if } 0 \leq \alpha<1 / 2 \\ \alpha / 5 & \text { if } 1 / 2 \leq \alpha \leq 1\end{cases}
$$

We shall prove that $T$ is a proximal quasi-contraction. Indeed, let

$$
u=(0, \alpha), \quad v=(0, \beta), \quad x=(0, \gamma), \quad y=(0, \delta) \in A_{0}
$$

such that

$$
d(u, T x)=d(v, T y)=d(A, B)=1 .
$$

It is easy to show that

$$
d(u, T x)=1 \quad \Longleftrightarrow \quad \alpha=f(\gamma)
$$

and

$$
d(v, T y)=1 \quad \Longleftrightarrow \quad \beta=f(\delta) .
$$

We distinguish three cases.

Case $1.0 \leq \gamma<1 / 2$ and $1 / 2 \leq \delta \leq 1$. In this case, we have

$$
\begin{aligned}
d(u, v) & =|f(\gamma)-f(\delta)|=\left|\frac{\gamma}{4}-\frac{\delta}{5}\right| \\
& \leq \frac{\gamma}{4}+\frac{\delta}{5}=\frac{1}{3}\left(\frac{3 \gamma}{4}\right)+\frac{1}{4}\left(\frac{4 \delta}{5}\right) \\
& \leq \frac{7}{12} \max \left\{\frac{3 \gamma}{4}, \frac{4 \delta}{5}\right\} \\
& =\frac{7}{12} \max \{d(x, u), d(y, v)\} \\
& \leq \frac{7}{12} \max \{d(x, y), d(x, u), d(y, v), d(x, v), d(y, u)\} .
\end{aligned}
$$


Case $2.0 \leq \gamma, \delta<1 / 2$. In this case, we have

$$
\begin{aligned}
d(u, v) & =|f(\gamma)-f(\delta)|=\frac{|\gamma-\delta|}{4} \\
& =\frac{d(x, y)}{4} \leq \frac{7}{12} \max \{d(x, y), d(x, u), d(y, v), d(x, v), d(y, u)\}
\end{aligned}
$$

Case $3.1 / 2 \leq \gamma, \delta \leq 1$. In this case, we have

$$
\begin{aligned}
d(u, v) & =|f(\gamma)-f(\delta)|=\frac{|\gamma-\delta|}{5} \\
& =\frac{d(x, y)}{5} \leq \frac{7}{12} \max \{d(x, y), d(x, u), d(y, v), d(x, v), d(y, u)\}
\end{aligned}
$$

Thus, we proved that $T$ is a proximal quasi-contraction mapping with $q=7 / 12$. Now, all the required hypotheses of Theorem 4.1 are satisfied, we deduce that $T$ has a unique best proximity point. In this example, $x^{*}=(0,0)$ is the unique best proximity point of $T$.

\section{Particular cases}

In this section, we will show that many recent best proximity point theorems can be deduced from our main result.

The following result can easily be deduced from Theorem 4.1 (see Remark 2.1).

Corollary 5.1 Let $(A, B)$ be a pair of subsets of a metric space $(X, d)$. Let $T: A \rightarrow B$ be a giving mapping. Suppose that the following conditions hold:

(i) $A_{0} \neq \emptyset$;

(ii) $A_{0}$ is proximal $T$-orbitally complete;

(iii) $T\left(A_{0}\right) \subseteq B_{0}$;

(iv) $T$ is a generalized proximal contraction of the first kind.

Then $T$ has a unique best proximity point $x^{*} \in A_{0}$. Moreover, for any $x_{0} \in A_{0}$, any sequence $\left\{x_{n}\right\} \in P P\left(x_{0}\right)$ converges to $x^{*}$.

Corollary 5.2 Let $(A, B)$ be a pair of closed subsets of a complete metric space $(X, d)$. Let $T: A \rightarrow B$ be a giving mapping. Suppose that the following conditions hold:

(i) $A_{0} \neq \emptyset$;

(ii) $B$ is approximatively compact with respect to $A$;

(iii) $T\left(A_{0}\right) \subseteq B_{0}$;

(iv) $T$ is a proximal quasi-contraction.

Then $T$ has a unique best proximity point $x^{*} \in A_{0}$. Moreover, for any $x_{0} \in A_{0}$, any sequence $\left\{x_{n}\right\} \in P P\left(x_{0}\right)$ converges to $x^{*}$.

Proof The result follows immediately from Theorem 4.1 and Lemma 3.1. Indeed, from Lemma 3.1, since $B$ is approximatively compact with respect to $A$, then $A_{0}$ is a closed subset of the complete metric space $(X, d)$, which implies that $A_{0}$ is proximal $T$-orbitally complete. So, we have only to apply Theorem 4.1 to get the desired result.

The following result due to [9] is an immediate consequence of Corollary 5.2. 
Corollary 5.3 Let $(A, B)$ be a pair of closed subsets of a complete metric space $(X, d)$. Let $T: A \rightarrow B$ be a giving mapping. Suppose that the following conditions hold:

(i) $A_{0} \neq \emptyset$;

(ii) $B$ is approximatively compact with respect to $A$;

(iii) $T\left(A_{0}\right) \subseteq B_{0}$;

(iv) $T$ is a generalized proximal contraction of the first kind.

Then $T$ has a unique best proximity point $x^{*} \in A_{0}$. Moreover, for any $x_{0} \in A_{0}$, any sequence $\left\{x_{n}\right\} \in P P\left(x_{0}\right)$ converges to $x^{*}$.

The following best proximity point result due also to [9] is a consequence of Corollary 5.1 and Lemma 3.2.

Corollary 5.4 Let $(A, B)$ be a pair of closed subsets of a complete metric space $(X, d)$. Let $T: A \rightarrow B$ be a giving mapping. Suppose that the following conditions hold:

(i) $T\left(A_{0}\right) \subseteq B_{0}$;

(ii) $T$ is a generalized proximal contraction of the first and second kind.

Then $T$ has a unique best proximity point $x^{*} \in A_{0}$. Moreover, for any $x_{0} \in A_{0}$, any sequence $\left\{x_{n}\right\} \in P P\left(x_{0}\right)$ converges to $x^{*}$.

Proof Since $(X, d)$ is complete and $T$ is a generalized proximal contraction of the second kind, it follows from Lemma 3.2 that $A_{0}$ is proximal $T$-orbitally complete. Now, the desired result can be obtained from Corollary 5.1.

Taking $X=A=B$ in Theorem 4.1, we obtain the famous Ćirićs fixed point theorem for quasi-contractive mappings (see [20]).

Corollary 5.5 Let $(X, d)$ be a metric space and let $T: X \rightarrow X$ be a quasi-contraction, that is,

$$
d(T x, T y) \leq q \max \{d(x, y), d(x, T x), d(y, T y), d(x, T y), d(y, T x)\},
$$

for all $x, y \in X$, where $q \in[0,1)$ is some constant. If $X$ is $T$-orbitally complete, then $T$ has a unique fixed point $x^{*} \in X$. Moreover, for any $x_{0} \in X$, the sequence $\left\{T^{n} x_{0}\right\}$ converges to $x^{*}$.

\section{Conclusion}

A new class of non-self-contractive mappings is introduced in this work. Under a proximal orbital completeness assumption, we established the existence and uniqueness of best proximity points for such mappings. We proved also that our proximal orbital completeness condition is weaker than the compactness condition and the proximal condition of second kind.

Competing interests

The authors declare that they have no competing interests.

Authors' contributions

All authors contributed equally and significantly in writing this paper. All authors read and approved the final manuscript.

Acknowledgements

The authors would like to extend their sincere appreciation to the Deanship of Scientific Research at King Saud University for its funding of this research through the Research Group Project no RGP-VPP-237. 


\section{References}

1. Raj Sankar, V: A best proximity point theorem for weakly contractive non-self-mappings. Nonlinear Anal. 74 4804-4808 (2011)

2. Caballero, J, Harjani, J, Sadarangani, K: A best proximity point theorem for Geraghty-contractions. Fixed Point Theory Appl. 2012, 231 (2012)

3. Gabeleh, M: Proximal weakly contractive and proximal nonexpansive non-self-mappings in metric and Banach spaces. J. Optim. Theory Appl. 158(2), 615-625 (2013)

4. Samet, B: Some results on best proximity points. J. Optim. Theory Appl. 159(1), 281-291 (2013)

5. Abkar, A, Gabeleh, M: A note on some best proximity point theorems proved under P-property. Abstr. Appl. Anal. 2013, Article ID 189567 (2013)

6. Sadiq Basha, S: Extensions of Banach's contraction principle. Numer. Funct. Anal. Optim. 31, 569-576 (2010)

7. Sadiq Basha, S: Best proximity point theorems generalizing the contraction principle. Nonlinear Anal. 74, 5844-5850 (2011)

8. Sadiq Basha, S: Best proximity point theorems: an exploration of a common solution to approximation and optimization problems. Appl. Math. Comput. 218, 9773-9780 (2012)

9. Sadiq Basha, S, Shahzad, N: Best proximity point theorems for generalized proximal contractions. Fixed Point Theory Appl. 2012, 42 (2012)

10. Al-Thagafi, MA, Shahzad, N: Convergence and existence results for best proximity points. Nonlinear Anal. 70 3665-3671 (2009)

11. Eldred, AA, Veeramani, P: Existence and convergence of best proximity points. J. Math. Anal. Appl. 323, 1001-1006 (2006)

12. De la Sen, M, Agarwal, RP: Common fixed points and best proximity points of two cyclic self-mappings. Fixed Point Theory Appl. 2012, 136 (2012)

13. Di Bari, C, Suzuki, T, Vetro, C: Best proximity points for cyclic Meir-Keeler contractions. Nonlinear Anal. 69, 3790-3794 (2008)

14. Karapinar, E: Best proximity points of cyclic mappings. Appl. Math. Lett. 25(11), 1761-1766 (2012)

15. Karapinar, E: Best proximity points of Kannan type cylic weak $\phi$-contractions in ordered metric spaces. An. Şt. Univ. Ovidius Constanţa. 20(3), 51-64 (2012)

16. Jleli, M, Karapinar, E, Samet, B: A best proximity point result in modular spaces with the Fatou property. Abstr. Appl. Anal. 2013, Article ID 329451 (2013)

17. Kirk, WA, Reich, S, Veeramani, P: Proximinal retracts and best proximity pair theorems. Numer. Funct. Anal. Optim. 24 851-862 (2003)

18. Pragadeeswarar, $\vee$, Marudai, M: Best proximity points: approximation and optimization in partially ordered metric spaces. Optim. Lett. 7(8), 1883-1892 (2013)

19. Vetro, C: Best proximity points: convergence and existence theorems for $p$-cyclic mappings. Nonlinear Anal. 73 , 2283-2291 (2010)

20. Ćirić, Lj: A generalization of Banach's contraction principle. Proc. Am. Math. Soc. 45, 267-273 (1974)

10.1186/1687-1812-2014-141

Cite this article as: Jleli and Samet: An optimization problem involving proximal quasi-contraction mappings. Fixed Point Theory and Applications 2014, 2014:141

\section{Submit your manuscript to a SpringerOpen ${ }^{\circ}$ journal and benefit from:}

- Convenient online submission

- Rigorous peer review

- Immediate publication on acceptance

- Open access: articles freely available online

- High visibility within the field

- Retaining the copyright to your article 